\title{
Article \\ Stability Analysis of Surrounding Rock in Multi-Discontinuous Hydraulic Tunnel Based on Microseismic Monitoring
}

\author{
Xiang Zhou ${ }^{1}$, Biao Li ${ }^{2,3, * \mathbb{D}}$, Chunming Yang ${ }^{4}$, Weiming Zhong ${ }^{5}$, Quanfu Ding ${ }^{3}$ and Haoyu Mao ${ }^{6}$ \\ 1 Chn Energy Dadu River Jinchuan Hydropower Construction, Jinchuan 624100, China; zhoux@stu.scu.edu.cn \\ 2 State Key Laboratory of Explosion Science and Technology, Beijing Institute of Technology, \\ Beijing 100081, China \\ 3 School of Geoscience and Technology, Southwest Petroleum University, Chengdu 610500, China; \\ dingquanfuswpu@163.com \\ 4 Chn Energy Dadu River Shuangjiangkou Hydropower Construction, Ma'erkang 624099, China; \\ ycmxaut@126.com \\ 5 PowerChina Chengdu Engineering Co., Ltd., Chengdu 610072, China; ringingclock@126.com \\ 6 State Key Laboratory of Hydraulics and Mountain River Engineering, College of Water Resource and \\ Hydropower, Sichuan University, Chengdu 610065, China; maohaoyu@stu.scu.edu.cn \\ * Correspondence: libiaoscu@163.com
}

Citation: Zhou, X.; Li, B.; Yang, C.; Zhong, W.; Ding, Q.; Mao, H. Stability Analysis of Surrounding Rock in Multi-Discontinuous Hydraulic Tunnel Based on Microseismic Monitoring. Appl. Sci. 2022, 12, 149. https://doi.org/ 10.3390/app12010149

Academic Editor: Fabrizio Balsamo

Received: 21 November 2021

Accepted: 21 December 2021

Published: 24 December 2021

Publisher's Note: MDPI stays neutral with regard to jurisdictional claims in published maps and institutional affiliations.

Copyright: (C) 2021 by the authors. Licensee MDPI, Basel, Switzerland. This article is an open access article distributed under the terms and conditions of the Creative Commons Attribution (CC BY) license (https:// creativecommons.org/licenses/by/ $4.0 /)$.

\begin{abstract}
The diversion tunnel of a hydropower station is characterized by low quality surrounding rock and weak structural planes. During excavation, rock mass spalling and cracking frequently occur. To evaluate the stability of a rock mass during tunnel excavation, high-precision microseismic monitoring technology was introduced to carry out real-time monitoring. Based on the temporal and spatial distribution characteristics of microseismic events, the main damage areas and their influencing factors of tunnel rock mass were studied. By analyzing the source characteristic parameters of the concentration area of microseismic activities, the rock fracture mechanism of the concentration area was revealed. The 3D numerical model of diversion tunnel was established, and the deformation characteristics of the rock mass under the control of different combination types of weak structural planes were obtained. The results showed that the microseismic event was active between 29 October 2020 and 6 November 2020, and the energy release increased sharply. The main damage areas of the rock mass were located at Stakes $\mathrm{K} 0+500-\mathrm{K} 0+600 \mathrm{~m}$. Microseismic source parameters revealed that shear failure or fault-slip failure induced by geological structures had an important influence on the stability of the surrounding rock. The numerical simulation results were consistent with the microseismic monitoring results and indicated that among the three kinds of structural plane combination types, including "upright triangle", "inverted triangle" and "nearly parallel", the "upright triangle" structure had the most significant influence on the stability of the surrounding rock. In addition, the maximum displacement of the surrounding rock had a trend of lateral migration to the larger dip angle in the three combined structural plane types. The research results will provide significant references for the safety evaluation and construction design of similar tunnels.
\end{abstract}

Keywords: hydraulic tunnel; microseismic monitoring; structural plane; numerical simulation; surrounding rock stability

\section{Introduction}

Southwest China is located in the first and second steps of China's three-step "staircase" topography, with complex terrain, numerous rivers, and abundant hydropower resources, accounting for $69 \%$ of China's total hydropower resources. With the rapid development of China's economy, the demand for energy is growing, and there is an urgent need for the exploitation and utilization of hydropower resources. A large number of hydropower stations are under construction or in the preparatory stage in Southwest China. Due to the rolling hills and deep valleys in this region, a large number of underground caverns need to be constructed for these hydropower stations. Against the background of complex 
geological conditions in the engineering area, various underground engineering problems arise, such as surrounding rock deformation during excavation, local collapse and rock bursts in a high-stress environment. These problems not only cause a lot of economic losses, but also seriously threaten the safety and life of on-site workers. Therefore, the evaluation and research of surrounding rock deformation and stability in underground engineering is an urgent need for hydropower engineering construction in Southwest China.

The conventional monitoring of stress, strain, displacement and deformation is widely used in the safety assessment of underground caverns. It can give quantitative monitoring results after the occurrence of large deformation in the surrounding rock but can hardly capture the microfractures formed during the stress adjustment of the deep rock mass in real time. However, the expansion and development of these microfractures are usually considered precursors to macroscopic instability and failure of the rock mass, so conventional monitoring has a certain time lag and space limitations. As a real-time 3D monitoring technology [1], microseismic monitoring allows determining the source information, such as the occurrence time, location, and intensity when surrounding rock fractures occur based on acoustic analysis, studying the expansion and evolution of surrounding rock microfractures, and analyzing the stability of the surrounding rock so as to give a warning or forecast for site construction. At present, microseismic monitoring is widely used in mines [2-4], tunnels [5-7], slope instability [8-12], the exploitation of oil, gas and geothermal energy [13-15], and underground storage [16] in Western countries as an effective means to study and prevent dynamic disasters in the rock mass. Arosio et al. [8] installed a microseismic monitoring system on a steep rock slope in northern Italy, and microseismic events caused by crack propagation and collapse were located and classified. The final results show that source location is a promising method to improve the final classification of microseismic events. Rutledge et al. [14] produced a high-resolution microseismic image of a hydraulic fracture stimulation in the Carthage Cotton Valley gas field of East Texas. The final results show that shear activation of these fractures indicates a stronger correlation of induced seismicity with low-impedance flow paths than is normally found or assumed during injection stimulation. The research and application of microseismic monitoring in China is relatively late. Specifically, microseismic monitoring was first used in the Mentougou Mine to monitor rock bursts in 1959 [17]. With the development of the mining industry, mining areas are facing various safety risks, and microseismic monitoring is widely promoted and applied to monitor the stability of mine-surrounding rock [18-21]. For example, Tang et al. [18] introduced microseismic monitoring into the Dongguashan Mine and applied the moment tensor theory to study the failure mechanism of the surrounding rock; Dou et al. [19] introduced microseismic monitoring into the Hujiahe Coal Mine, Binchang Mining Area, Shaanxi, and proposed a comprehensive warning model for rock bursts based on the microseismic precursor indicator system; and Jiang et al. [20] adopted microseismic monitoring to trace and evaluate fractures in hydraulic fracturing of coal seams. In recent years, hydropower stations have been built in Southwest China to provide energy support for national development. Due to complex geological conditions and frequent occurrence of various engineering and geological disasters, microseismic monitoring has been gradually applied to the hydropower industry, providing a new method to ensure construction safety. Feng et al. [22,23] applied microseismic monitoring to Jinping-II hydropower station to study microseismic activities, TBM boring, and the occurrence of rock bursts, and predict or forecast the occurrence of rock bursts during TBM boring in deep-buried tunnels; Tang et al. [24] used the microseismic monitoring system to obtain the source information and applied the loading/unloading response ratio theory to predict the slope failure during water storage in the Dagangshan hydropower station; Tang et al. [25] studied and predicted the hazard of rock bursts in the tunnel of the Jinping-II hydropower station using microseismic monitoring, indicating that the technology can be used to capture seismic activities in the stress formation and warning period; $\mathrm{Xu}$ et al. [26-28] carried out microseismic monitoring in the Jinping-I, Shuangjiangkou, and Houziyan hydropower stations, studied the evolution process of microfractures and 
the formation process of rock deformation inside the surrounding rock in blasting and excavation based on the monitoring results, and gave a warning or forecast, thus ensuring the site construction safety.

The deformation and failure of hydraulic tunnels is usually affected by various factors, such as the geostress, excavation unloading, and geological structure. The failure evolution mechanism of the rock mass dominated by different factors is the basis of the stability analysis. In this study, a microseismic monitoring system was established in the diversion tunnel of a hydropower station. Based on the spatial and temporal characteristics of microseismic activities during the excavation, the main damage areas of the rock mass were delineated. Under the site construction and geological conditions, the main factors causing damage to rock mass were revealed. The characteristics of the microseismic source parameters in typical periods were analyzed. The damage evolution mechanism was discussed. Finally, a 3D numerical model of the multi-discontinuous tunnel areas was established and compared with the microseismic monitoring results. It is worth noting that three structural planes with different combination types appear in a short tunnel. Secondly, microseismic monitoring technology is used to track the fracture damage of surrounding rock in this section, and numerical calculation model is used to verify it. The results reveal which type of combined structure has the greatest influence on the tunnel. The research results can provide a better understanding of the rock mass fracturing mechanism and failures of this hydraulic tunnel and other similar tunnels.

\section{The Study Site}

The studied hydropower station is at the sixth level of the planned hydropower stations on the main stream of Dadu River. Figure 1 shows the location of the hydropower station. The dam site is located about $13 \mathrm{~km}$ north of a county, on an about $1 \mathrm{~km}$ upstream reach of the confluence of the Dadu River and the right bank tributary Xinzagou River. The river valley is reverse-S-shaped on the plane, and the river generally flows from SE140 $150^{\circ}$ at Cuijiahe Dam to SW $190^{\circ}-200^{\circ}$, and then to SW230 $-240^{\circ}$ through the dam site area. The river valley is V-shaped, with an about $2153 \mathrm{~m}$ water level during the dry season and an about 50-90 m wide water surface. Normally, the water level is $2253 \mathrm{~m}$ and the corresponding valley is about $245-310 \mathrm{~m}$ wide. The reservoir area of this hydropower station is about $32.9 \mathrm{~km}$ long, with a normal water level of $2253 \mathrm{~m}$, a dead water level of $2248 \mathrm{~m}$, and a storage capacity of about 488 million $\mathrm{m}^{3}$. The hydropower station consists of the dam, diversion structure, power generation structure, water discharge structure, access tunnel, accessory structures, and temporary construction structures.

The diversion tunnel is $1042.87 \mathrm{~m}$ long, with an inlet at $\mathrm{SW} 245^{\circ}$ and an outlet at $\mathrm{SW} 200^{\circ}$ in the axial direction. The maximum vertical burial depth is $380 \mathrm{~m}$, and the occurrence of the rock formation is $\mathrm{NW} 320^{\circ}-330^{\circ} \mathrm{SW} \angle 60^{\circ}-89^{\circ}$. The fractures are mainly bedding plane fractures and bedding faults. Most of the tunnel sections are below the water table, and the surrounding rock of the whole tunnel is mainly IV1 and III1 (III1 accounting for $37.0 \%$, III2 accounting for $19.4 \%$, IV1 accounting for $38.6 \%$, and IV2 accounting for $5.0 \%$ ). The IV1 and IV2 rock masses are mainly located in the inlet section of the tunnel and the weak interlayer in the middle of the cavern. The stability of the surrounding rock is poor and requires support treatment. Figure 2 shows the geological profile, 3D model, and typical section of the diversion tunnel. 


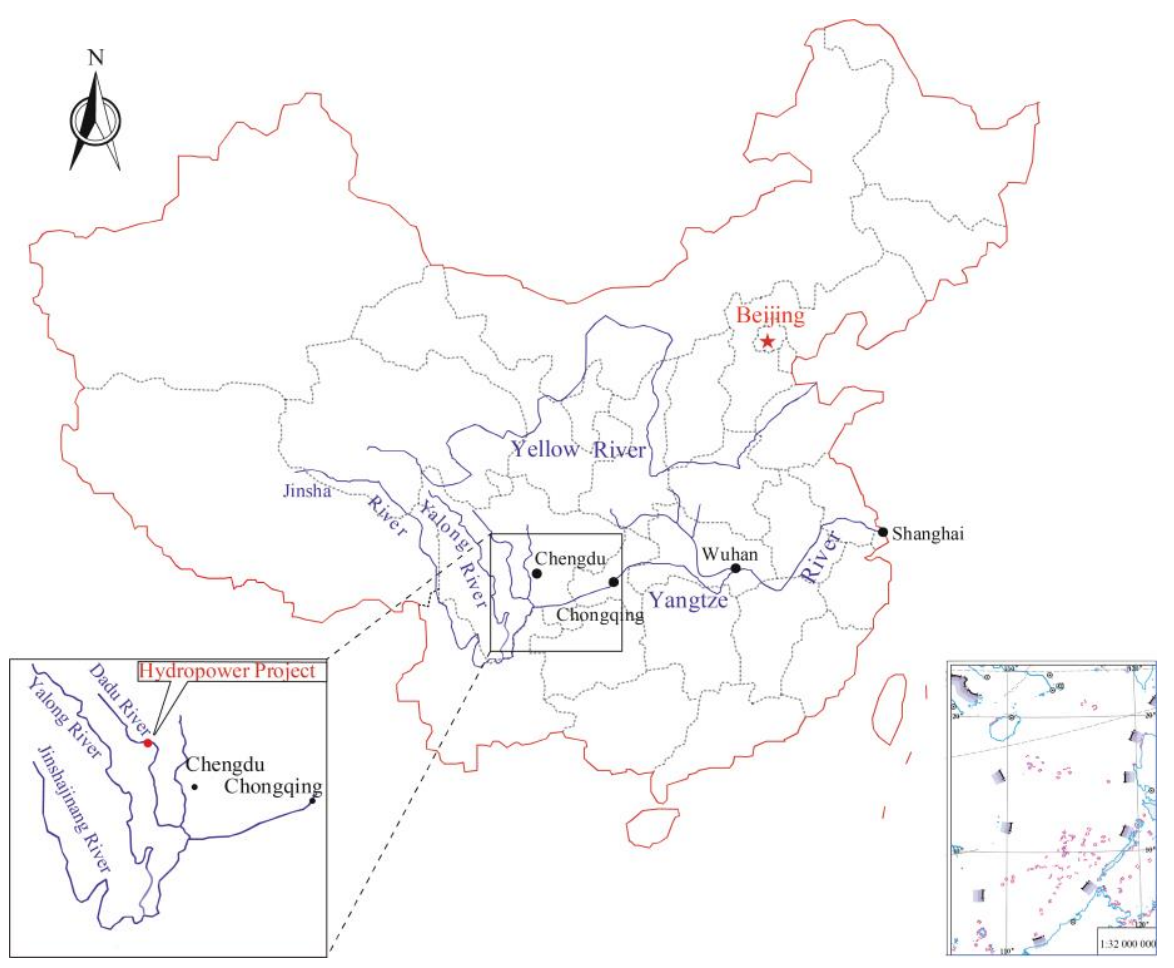

Figure 1. The location of the hydropower station.

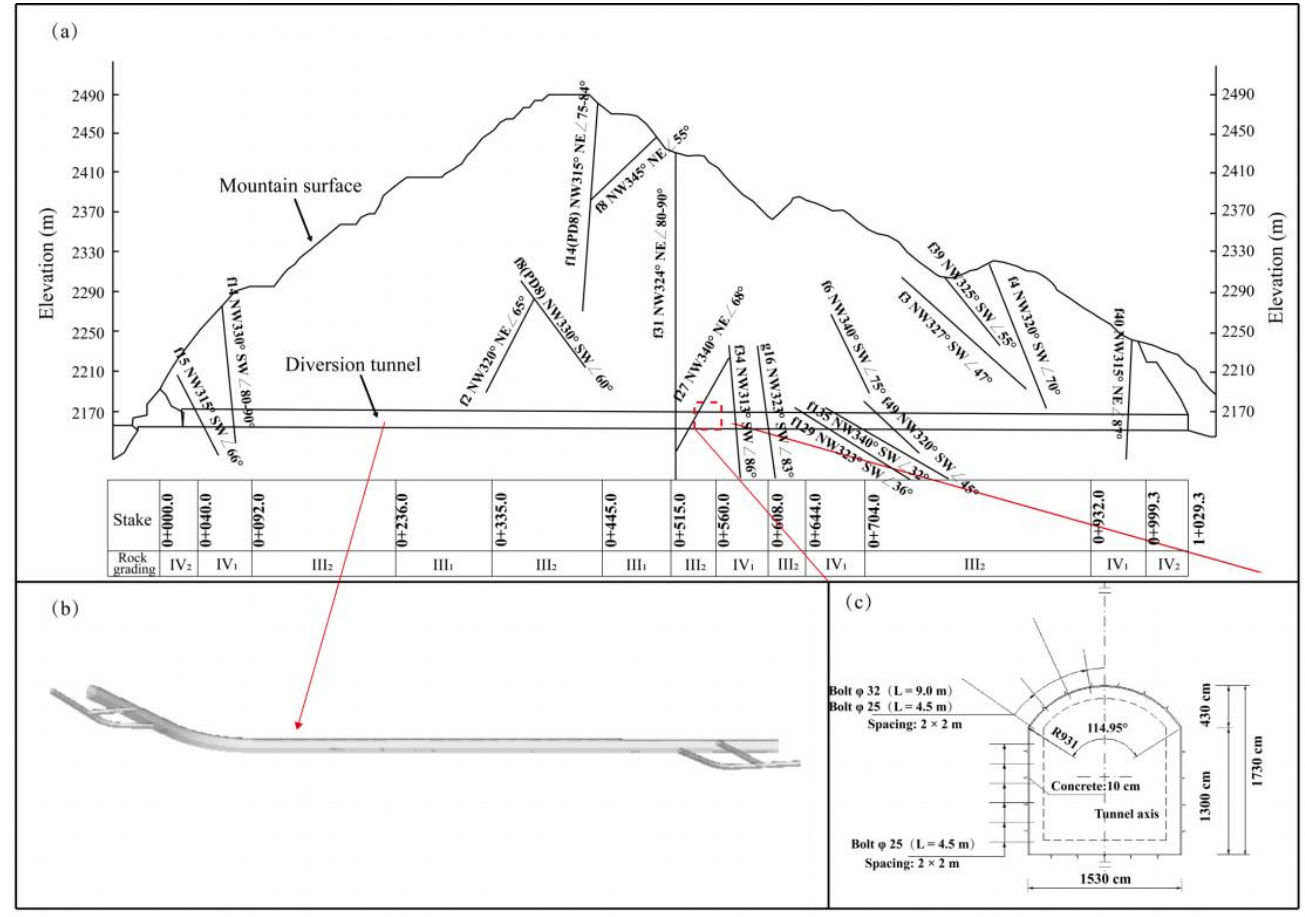

Figure 2. Tunnel profile. (a) Profile information; (b) 3D model; (c) typical section of the diversion tunnel.

\section{Construction of the Microseismic Monitoring System}

\subsection{Composition of the Microseismic Monitoring System}

When rock mass in underground engineering suffers from external disturbance, the surrounding rock stress changes, and the elastic energy accumulates locally. Once the energy reaches the critical value, microfractures are formed in the rock mass and elastic waves are released simultaneously, which are called microseismic activities. The source 
information, such as the occurrence time, location, and energy of microfractures, is obtained based on analysis of the acoustic signals of rock fractures.

Relying on the diversion tunnel of this hydropower station, a microseismic monitoring system was established. Figure 3 shows the network topology of the monitoring system. The elastic waves emitted by rock fractures are received by the sensors and transmitted via the cable to the signal conversion device to form the original waveforms recording the source information, which is transmitted to the camp office by wireless network and finally sent to the analysis center for data interpretation via the internet.

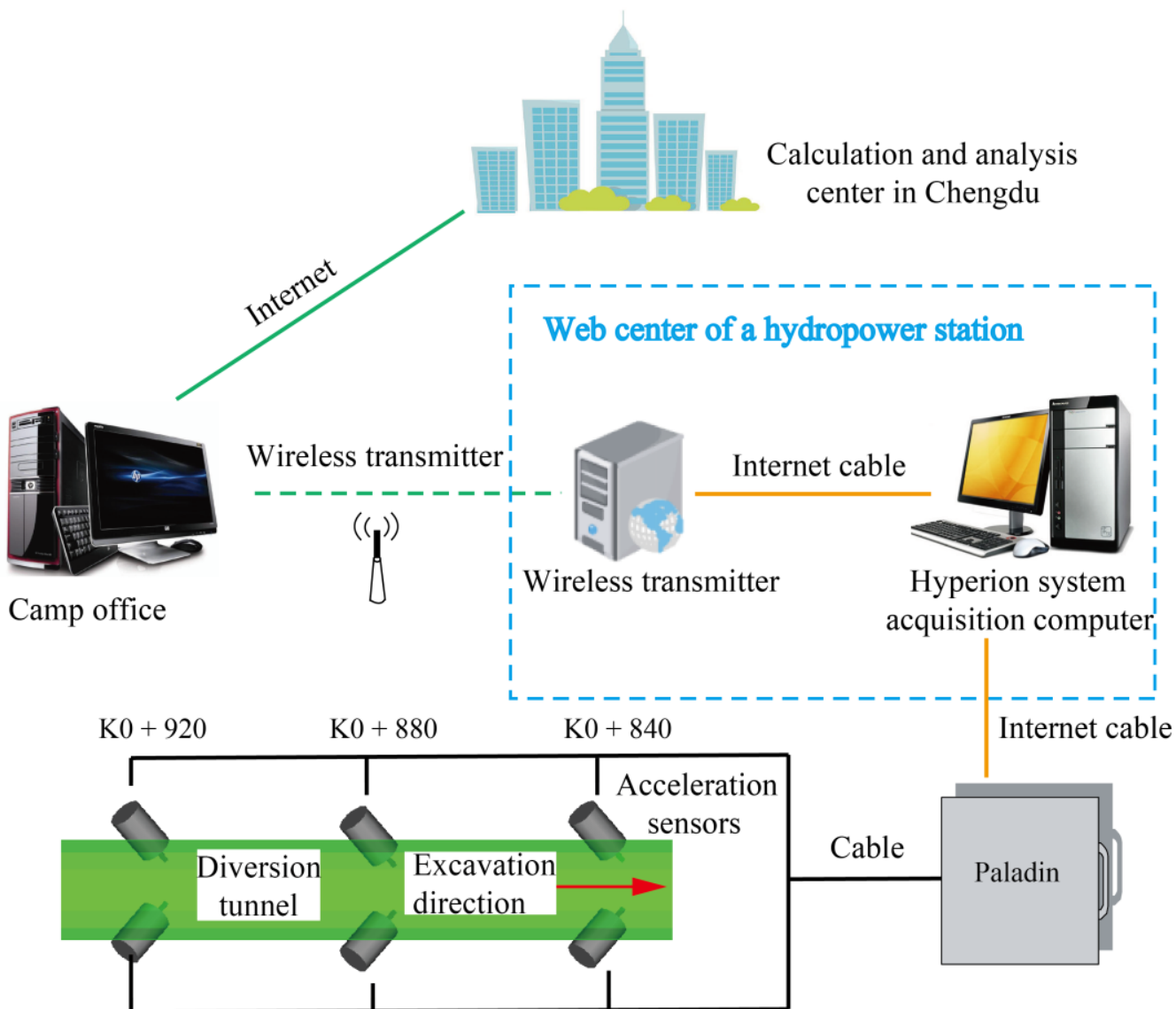

Figure 3. Topology diagram of the microseismic monitoring system in the diversion tunnel of the hydropower station.

\subsection{Dynamic Deployment of Sensors}

Six sensors were installed in both sidewalls in a symmetrical manner after tunnel excavation. If the distance between adjacent sensors is less than $35 \mathrm{~m}$, the time difference for P-wave pickup is too small and the accuracy decreases. If the P-wave pickup time difference is too small, it is not conducive to the location of microseismic events. If the sensor is too far from the tunnel face, it is difficult for the sensor to receive fracture signals effectively. In order to achieve the best monitoring effect and avoid destruction to the monitoring cables caused by blasting, the distance between adjacent sensors was set to $40 \mathrm{~m}$, and that between the tunnel face and the sensor closest to it was set to $30 \mathrm{~m}$ (as shown in Figure 4). Once the distance between the tunnel face and the sensor closest to it is $70 \mathrm{~m}$, the two sensors farthest away from the tunnel face are moved to be close to it. With this dynamic adjustment, the rock fracture signals around excavation areas can be sufficiently captured. 


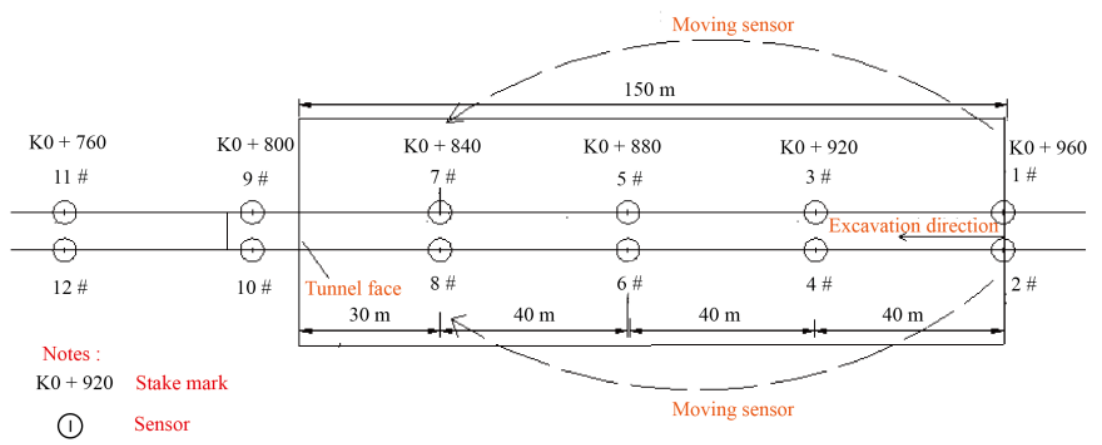

Figure 4. Layout of sensors in the diversion tunnel.

\section{Characteristics of Microseismic Activities during Excavation of the Diversion Tunnel}

\subsection{Temporal Distribution Characteristics of Microseismic Events}

The microseismic monitoring system in the diversion tunnel of this hydropower station was put into operation on 30 July 2020 and had identified 374 microseismic activities in an effective spatial range by 18 December 2020. Figure 5 shows the waveforms of several typical signals. As shown in Figure 5a, the MS signal has a relatively low intensity with the peak amplitude of about dozens to hundreds of millivolts. It has a lower frequency than the blasting signal. The blasting signal usually has a high intensity with the peak amplitude at approximately $4500 \mathrm{mV}$. It also has a high frequency and several regular waveforms in a window, as shown in Figure 5b. As shown in Figure 5c, the mechanical vibration signal has several waveforms in a window. These waveforms attenuate quickly. In addition, the waveforms attenuate relatively slowly compared to blasting waveforms. The electric signal usually has a low amplitude less than $10 \mathrm{mV}$ and a stable frequency about $50 \mathrm{~Hz}$, as shown in Figure 5d. Figure 6 shows the number of microseismic events in a single day. As seen from the figure, the number of daily microseismic events is low overall, 2 to 4 mostly. Microseismic activities are relatively frequent from 29 October to 6 November, and there is a sudden increase in the number of daily microseismic events, up to 9. Moreover, based on the energy dissipation principle, microfractures in the surrounding rock (microseismic activities) represent damage to the surrounding rock, and each microfracture of the surrounding rock is accompanied by the release of energy. The cumulative energy release curve of microseismic events also presents an obvious increment from 29 October to 6 November, which indicates that microseismic activities are frequent during this period and accompanied by rapid energy release. Thus, this period was selected as the focus of the study.

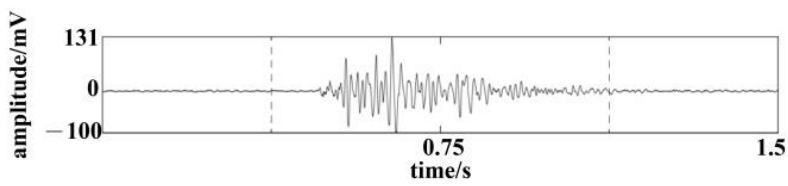

(a)Typical microseismic signals

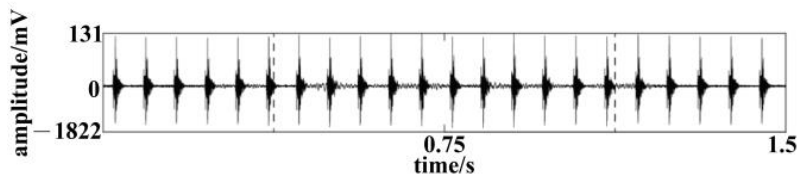

(c)Typical construction signal

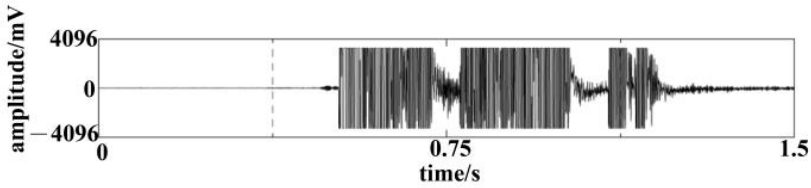

(b)Typical burst signal

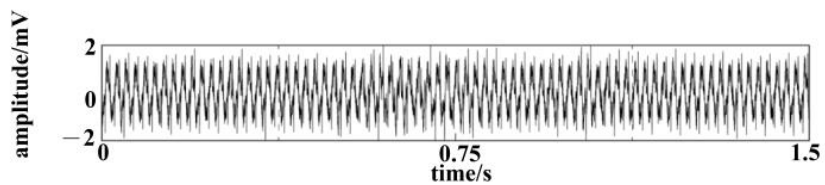

(d)Typical current signa

Figure 5. Waveforms of typical signals. 


\section{Total number of events: 374}

From: 30.07.2020 00:00:00 North: $-300 \sim 300$

East: $\quad-\mathbf{3 0 0} \sim \mathbf{3 0 0}$

Depth: 2100 2200

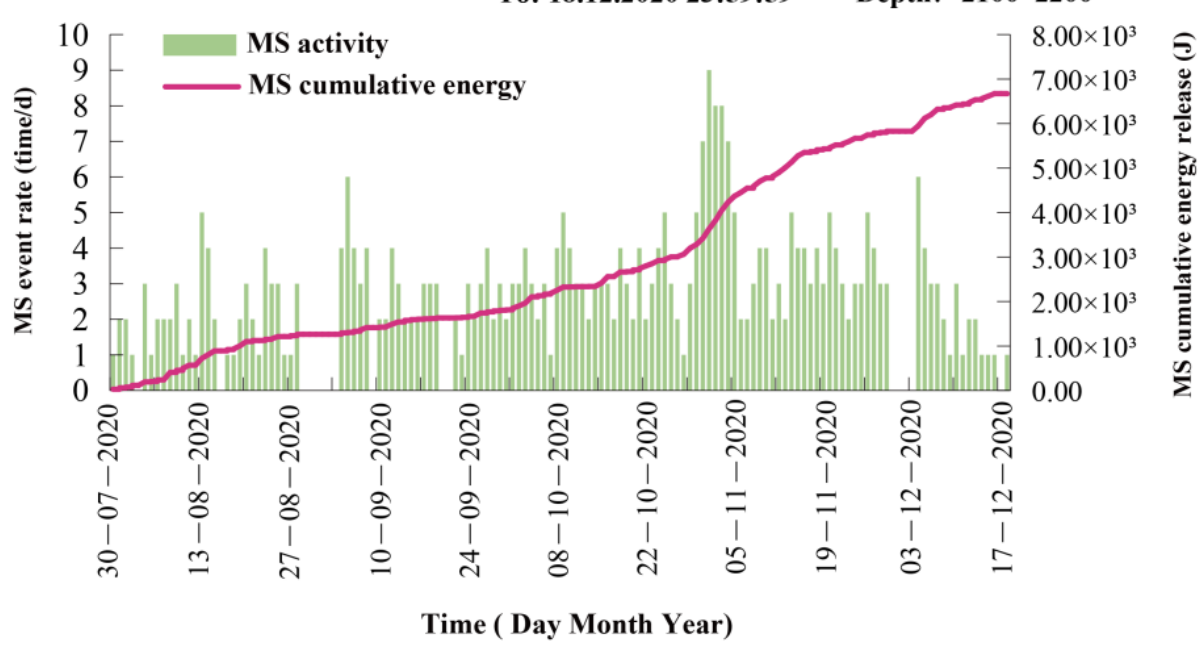

Figure 6. Relationships among the activity rate of microseismic events, accumulative energy loss, and time.

\subsection{Spatial Distribution Characteristics of Microseismic Events}

Figure 6 shows the spatial distribution and density contours of microseismic events in the diversion tunnel of the hydropower station from 30 July 2020 to 18 December 2020. As shown in Figure 7a,b, most of the microseismic events are distributed along the tunnel trunk, and there are more microseismic events on the arch than in the sidewall. Figure 7c,d illustrates that microseismic events are mainly distributed at stakes $\mathrm{K} 0+500-\mathrm{K} 0+600$, with an obvious concentration at stake $\mathrm{K} 0+540$ and certain concentration at stake $\mathrm{K} 0+$ 570. Moreover, there are more microseismic events in the right sidewall than in the left sidewall and on the right arch than on the left arch (from large stake numbers to small ones). Combined with the site construction conditions, it can be seen that the diversion tunnel was excavated using the drilling and blasting method at Stakes K0 + 480-K0 + 640 from 1 October to 10 November. During this period, the spillway tunnel on the right of the diversion tunnel was under construction simultaneously. The blasting excavation of the spillway tunnel caused disturbance to the rock mass between the two tunnels, and after the excavation of the two tunnels, two free faces were formed. Thus, two-way unloading occurred in the rock mass, which is prone to fractures and microseismic events in the case of low rock strength. In addition, it is clearly evident from the geological profile that there are four weak structural planes at Stakes $\mathrm{K} 0+500-\mathrm{K} 0+650$, further deteriorating the rock quality of this tunnel section and increasing surrounding rock fractures under construction disturbance.

\subsection{Characteristic Parameter Analysis of Microseismic Activities in Special Periods}

\subsubsection{Es/Ep Eigenvalues}

Es/Ep, the ratio of S-wave energy to P-wave energy, is an important indicator in seismology that reflects the damage mechanism of surrounding rock. Boatwright and Fletcher [29] found that $E s / E p \geq 10$ usually in shear failure or fault slips, and $E s / E p \leq 3$ in non-shear failure, due to factors such as tensile failure and volumetric stress changes.

The diversion tunnel of the hydropower station was excavated at Stakes K0 + 510$\mathrm{K} 0+565 \mathrm{~m}$ from 20 October to 10 November 2020. Figure 8 shows that the number of microseismic events with $E s / E p$ values less than 3 accounts for $31 \%$ of the total microseismic events in this period, while that with Es / Ep values larger than 10 is $39 \%$, indicating that fractures of the rock mass in this area include tensile and shear failures. Combined with the geological conditions in the area, it can be seen that the stress is concentrated on the 
weak structural plane due to excavation unloading, resulting in tensile cracks on both sides near the structural plane, which are continuously extended on the structural plane. In addition, many fault joints are distributed in the diversion tunnel, and under the influence of construction, the loose rock mass near the structural plane is prone to slips and shear failure along the structural plane.
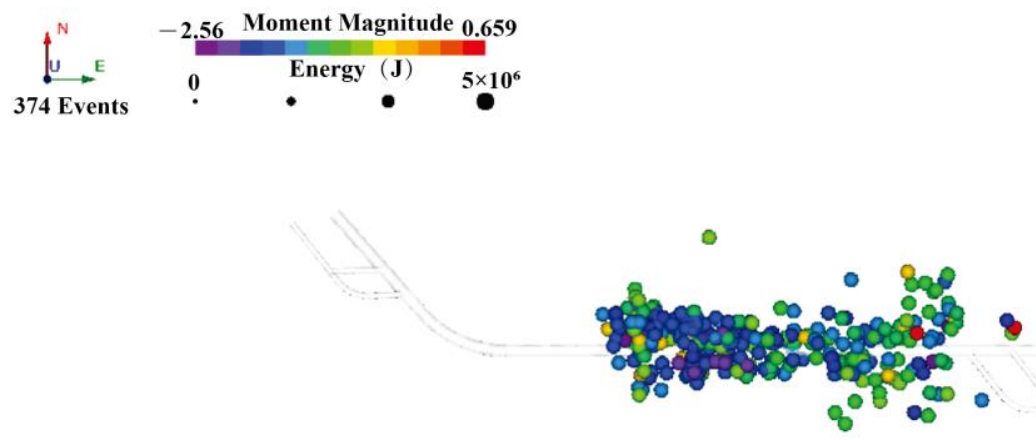

(a)
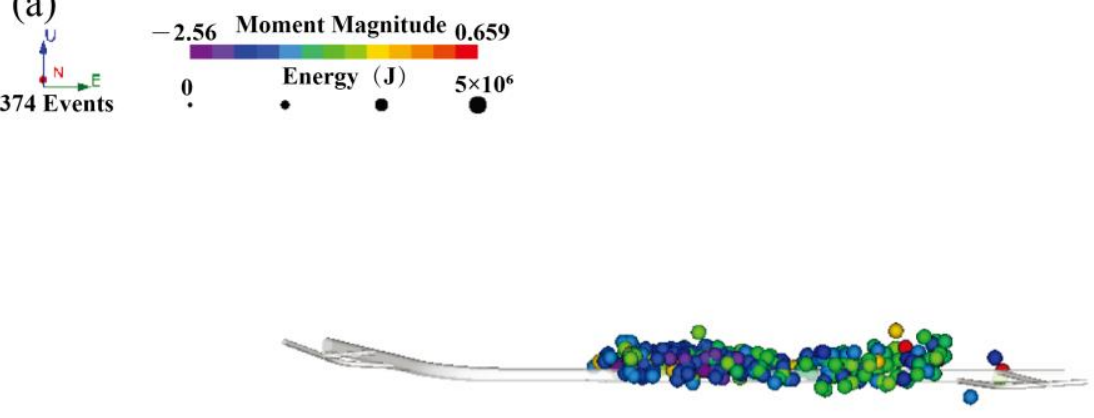

(b)

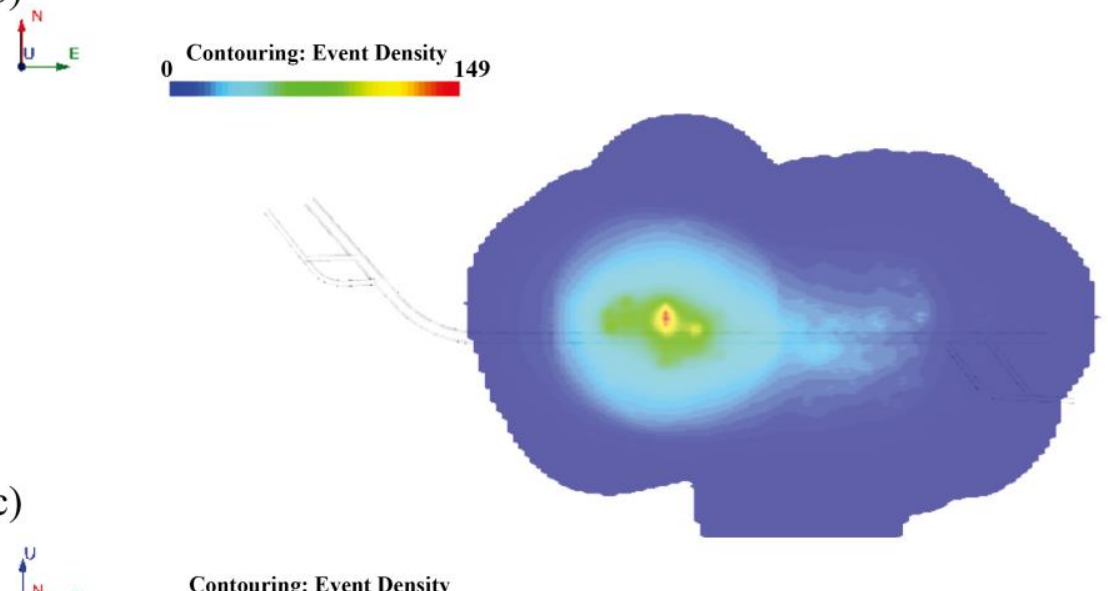

$\stackrel{N}{\longrightarrow} \quad 0^{\text {Contouring: Event Density }} 312$

(d)

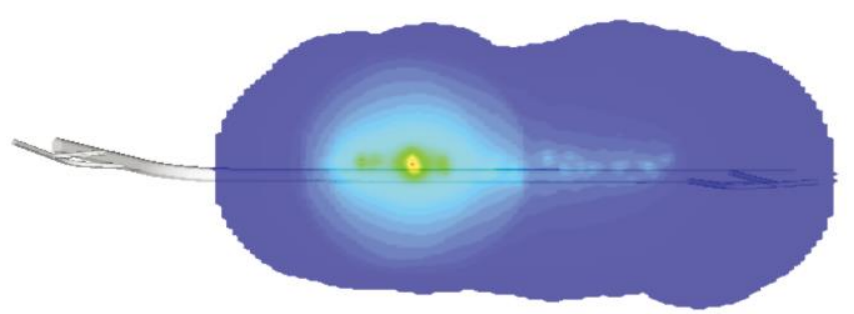

Figure 7. Spatial distributions and density cloud map of microseismic events (30 July 2020 to 18 December 2020). (a) Top view; (b) side view;(c) top view; (d) side view. 


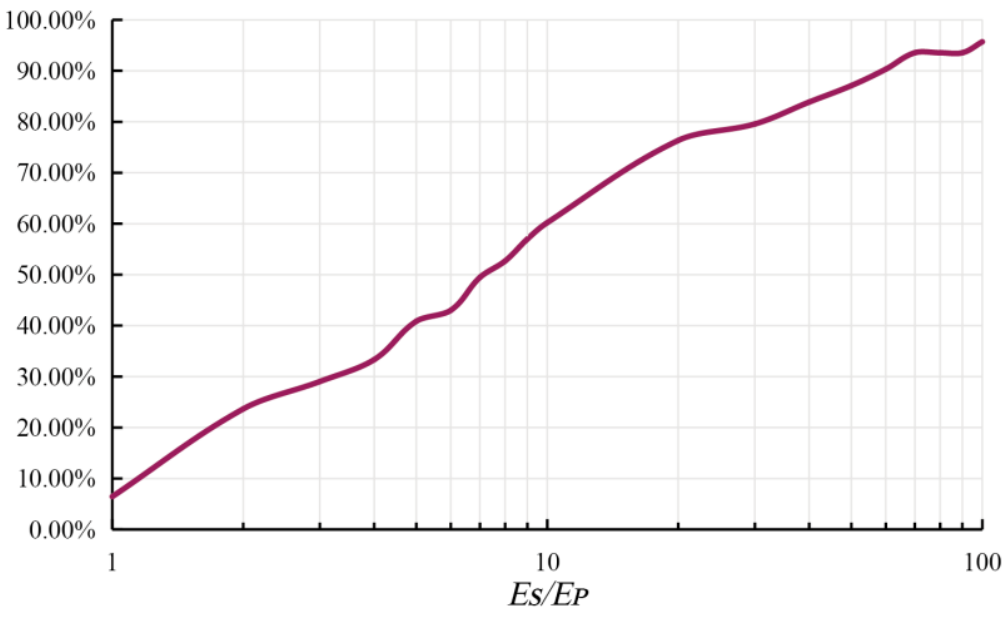

Figure 8. Percentage distribution of $E_{S} / E_{P}$ values (20 October 2020 to 10 November 2020).

\subsubsection{Magnitude-Frequency Relationship ( $b$-Value)}

Gutenberg and Richter [30] applied a linear fit to the relationship between earthquake magnitude and frequency and proposed the well-known Gutenberg-Richter law (GR law). The formula is as follows:

$$
\lg N=a-b m_{\mathrm{M}}
$$

where $m_{\mathrm{M}}$ is the earthquake magnitude; $N$ is the number of seismic events with a magnitude greater than or equal to $m_{\mathrm{M}}$; and $a$ and $b$ are two constants that can be obtained by linear fitting for a given set of data. The parameter $b$ has a special physical meaning that reveals the proportion of events with different magnitudes. Legge and Spottiswoode [31] studied the magnitude-frequency characteristics of microseismic activities during mining and concluded that microseismic activities caused by fault slips tend to have smaller $b$-values (generally less than 0.8 ), while the $b$-values of microseismic activities induced by blasting in mining are relatively high (1.2 to 1.5$)$.

Similarly, the GR law is applicable to microseismic events in engineering. A linear fit was applied to the magnitude and frequency of the microseismic events from 20 October to 10 November 2020 at an interval of $\Delta \mathrm{M}=0.05$. Figure 9 shows the relationship between magnitude and frequency. The $b$-value in this period is 1.0, which is between the typical $b$-values of the two types of microseismic activities. It means that there are microseismic activities caused by blast-induced stress migration and by slips on the structural plane in this period, which is consistent with the site working conditions.

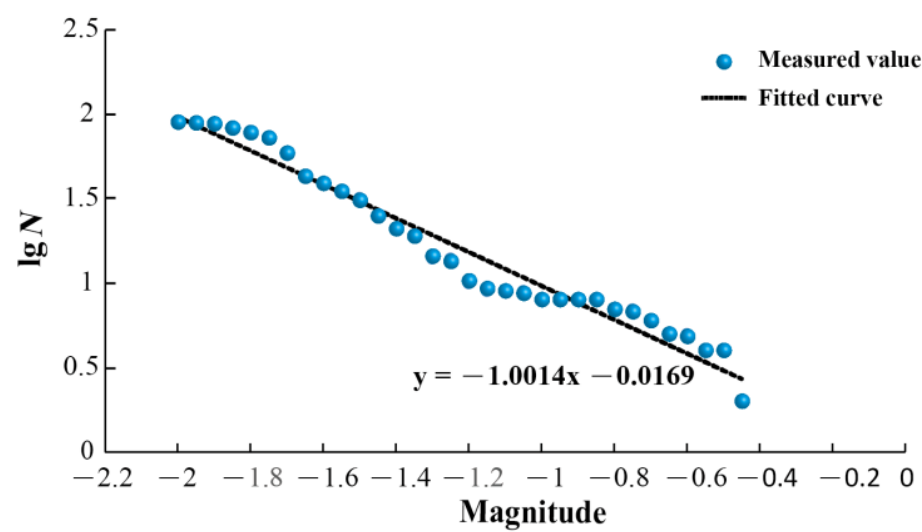

Figure 9. Relationship between magnitude and frequency of microseismic events (20 October 2020 to 10 December 2020). 


\section{3D Numerical Simulation Using FLAC 3D}

\subsection{D Numerical Model}

A $500 \mathrm{~m} \times 150 \mathrm{~m} \times 300 \mathrm{~m}$ 3D numerical model was established for the tunnel section at Stakes $\mathrm{K} 0+300-\mathrm{K} 0+800$ based on the geological environment of the diversion tunnel and tunnel excavation dimensions. The Mohr-Coulomb elastic-plastic constitutive relationship was adopted into this model and a total of 1,052,196 elements were divided, as shown in Figure 10a. In the 3D numerical model, several weak structural planes near the concentration area of microseismic activities were considered, and grids in this tunnel section model were locally densified, as shown in Figure 10b. The mechanical parameters of the rock mass and structural planes of the 3D numerical model are listed in Tables 1 and 2.

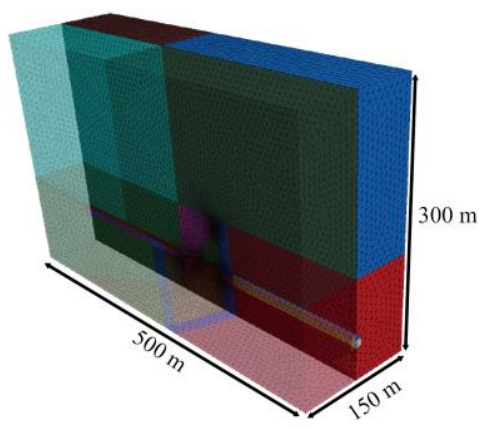

(a)

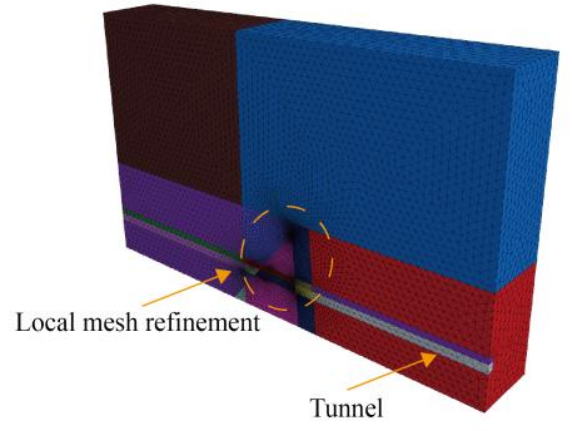

(b)

Figure 10. The 3D numerical model. (a) Complete model; (b) half of the model.

Table 1. Surrounding rock parameters.

\begin{tabular}{ccccccc}
\hline $\begin{array}{c}\text { Surrounding } \\
\text { Rock Grade }\end{array}$ & $\begin{array}{c}\text { Density } \\
\left(\mathbf{k g} / \mathbf{m}^{3}\right)\end{array}$ & $\begin{array}{c}\text { Deformation } \\
\text { Modulus } \\
(\mathrm{GPa})\end{array}$ & $\begin{array}{c}\text { Elastic } \\
\text { Modulus } \\
(\mathrm{GPa})\end{array}$ & $\begin{array}{c}\text { Poisson's } \\
\text { Ratio }\end{array}$ & $\begin{array}{c}\text { Internal Friction } \\
\text { Angle }\left({ }^{\circ}\right)\end{array}$ & $\begin{array}{c}\text { Cohesion } \\
(\mathbf{M P a})\end{array}$ \\
\hline IV1 & 2600 & 4 & 4.5 & 0.3 & 35 & 0.4 \\
\hline
\end{tabular}

Table 2. Structural plane parameters.

\begin{tabular}{ccc}
\hline Structural Plane & Internal Friction Angle ( ${ }^{\circ}$ ) & Cohesion (MPa) \\
\hline Weak structural plane (debris with mud) & 22 & 0.07 \\
\hline
\end{tabular}

\subsection{Numerical Simulation Results}

There are four weak structural planes close to each other at Stakes K0 + 500-K0 + 620 in the diversion tunnel, in which microseismic activities were concentrated in layer-1 excavation of the diversion tunnel. Therefore, this region is the key position to study surrounding rock stability of the diversion tunnel. To explore the impact of weak structural planes on the stability of surrounding rock in the diversion tunnel, no support measures were imposed on this numerical simulation model. The numerical model calculation took 5 days. Figure 11 illustrates the displacement of the diversion tunnel trunk at Stakes K0 + $500-\mathrm{K} 0+620$. It can be seen that the maximum displacement of $17 \mathrm{~cm}$ is at Stake $\mathrm{K} 0+568$ near the diversion tunnel trunk. 


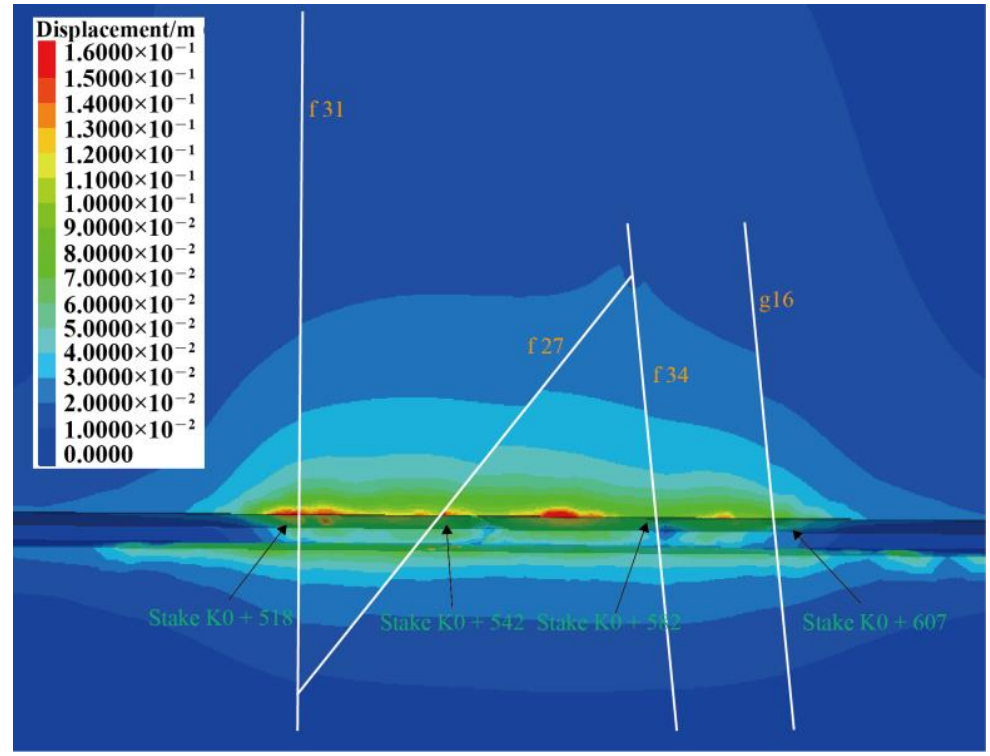

Figure 11. Displacements at stakes $\mathrm{K} 0+500-\mathrm{K} 0+620$ of the diversion tunnel.

As shown in Figure 11, four weak structural planes form three types of structural plane combinations, namely, the "nearly parallel" structural plane combination by g16 and f34, "upright triangle" combination by f34 and f27, and "inverted triangle" combination by $\mathrm{f} 27$ and f31. After the tunnel excavation, the surrounding rock inside the "upright triangle" structural plane has the largest displacements, with the maximum displacement of $17 \mathrm{~cm}$. The surrounding rock inside the "inverted triangle" structural plane has relatively small displacements, with the maximum displacement of $15 \mathrm{~cm}$. The surrounding rock inside the "nearly parallel" structural plane has the smallest displacements, with the maximum displacement of $12 \mathrm{~cm}$. It is presumed that the rock mass in the "upright triangle" structural plane forms an "upright wedge" with a large bottom, which has a greater tendency to slip downward under the action of gravity and stress adjustment. However, the rock mass in the "inverted triangle" structural plane forms an "inverted wedge" with a small bottom, and the lower surrounding rock plays a certain role in blocking the slip. In addition, the structural plane combination has an offset to the side of the structural plane with a larger dip angle at the maximum displacement of the surrounding rock. For example, the "nearly parallel" structural plane has an offset to g16; the "upright triangle" has an offset to f34 and the "inverted triangle" has an offset to f31.

Figure 12 shows the front view profile of displacements at the intersection of four weak structural planes and the diversion tunnel trunk. Specifically, the displacement of the surrounding rock at the intersection of the diversion tunnel trunk and g16, f34, f27, and f31 is $11,13,15$, and $16 \mathrm{~cm}$, respectively. The largest displacement appears at the intersection of the diversion tunnel trunk and f31. It is assumed that the dip angle of $\mathrm{f} 31$ is too large, which leads to the large displacement of the rock mass at the intersection under the action of gravity and stress adjustment of the surrounding rock.

As previously indicated, microseismic activities are concentrated at Stakes $\mathrm{K} 0+540$ and $\mathrm{K} 0+570$, the maximum displacement in the numerical simulation is at Stake $\mathrm{K} 0+568$, and a relatively large displacement is generated at stake $\mathrm{K} 0+542$, which indicates that the distribution of microseismic activities closely coincides with the numerical simulation results. 


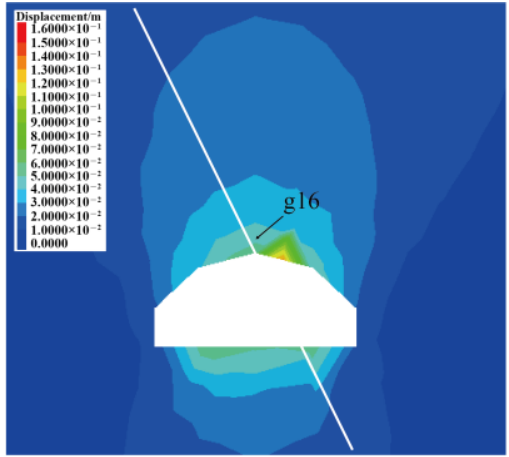

(a)

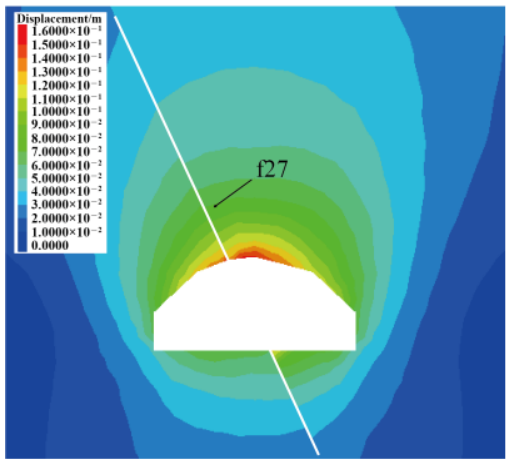

(c)

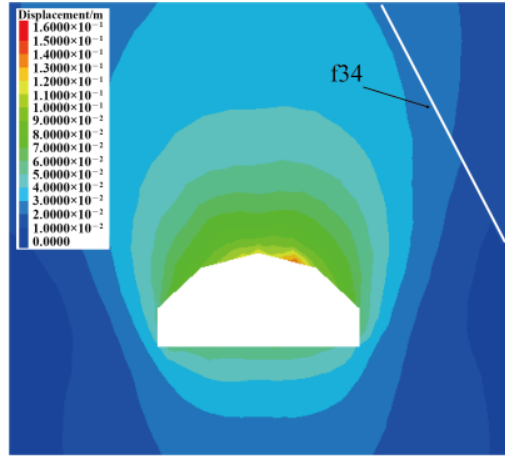

(b)

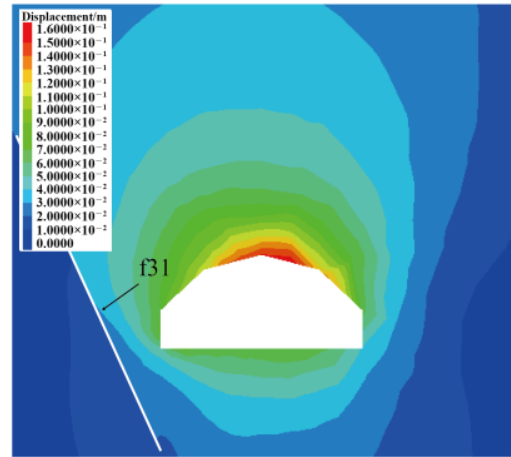

(d)

Figure 12. Displacements at the intersection of structural planes and the diversion tunnel trunk: (a) Stake K0 + 607; (b) Stake K0 + 582; (c) Stake K0 + 542; (d) Stake K0 + 518 .

\section{Conclusions}

Microseismic monitoring was introduced into the diversion tunnel of a hydropower station to monitor, analyze and evaluate the stability of the surrounding rock during tunnel excavation. The following conclusions were drawn based on the analysis of the characteristics of microseismic activities and numerical simulation results.

The diversion tunnel had frequent microseismic activities from 29 October to 6 November 2020, with up to nine microseismic events in a single day, along with a dramatic rise in the cumulative energy release curve. Microseismic events were mainly distributed at Stakes $\mathrm{K} 0+500-\mathrm{K} 0+600$ and particularly concentrated at Stakes $\mathrm{K} 0+540$ and $\mathrm{K} 0+570$, where damage of the surrounding rock was serious. Excavation unloading, structural planes and the group tunnel effect were the main factors causing microseismic events in the diversion tunnel.

From 20 October to 10 November 2020, the diversion tunnel was excavated at Stakes $\mathrm{K} 0+510-\mathrm{K} 0+565$. The Es $/ E p$ characteristics of microseismic events revealed that fractures of rock mass included tensile and shear failures. The stress was concentrated on the weak structural plane due to excavation and unloading, resulting in tensile cracks on both sides of the structural plane. Four structural planes and the loose rock mass near the structural plane was prone to slips and shear failure along the structural plane. The $b$-value of micreoseismic events was 1.0, indicating that there were microseismic activities caused by blast-induced stress migration and by slips on the structural plane.

There are three types of structural plane combinations, namely "nearly parallel", "upright triangle" and "inverted triangle", at Stakes $\mathrm{K} 0+500-\mathrm{K} 0+620$. The numerical simulation results showed that the "upright triangle" structural plane had the greatest influence on the deformation of the rock mass within its range, followed by the "inverted triangle" structural plane, and finally the "nearly parallel" structural plane. In addition, the structural plane combination had an offset to the side of the structural plane with a 
larger dip angle at the maximum displacement of the surrounding rock. The distribution of microseismic activities was in good agreement with the numerical simulation results. Surrounding rock damage was serious around microseismic clusters, which was prone to surrounding rock deformation and failure and had great guiding significance for site construction safety and engineering warning.

It is worth noting that three structural planes with different combination types appear in a short tunnel. Secondly, microseismic monitoring technology is used to track the fracture damage of surrounding rock in this section, and the numerical calculation model is used to verify it. The results reveal which type of combined structure has the greatest influence on the tunnel. The research results can provide a better understanding of the rock mass fracturing mechanism and failures of this hydraulic tunnel and other similar tunnels.

Author Contributions: X.Z. conducted the literature review and wrote the first draft of the manuscript. B.L. developed the overarching research goals and analyzed microseismic source parameters. C.Y. edited the draft of the manuscript. W.Z. investigated the geological and construction information of the engineering. Q.D. carried out the numerical simulation. H.M. processed the microseismic monitoring data. All authors have read and agreed to the published version of the manuscript.

Funding: The research is supported by the National Natural Science Foundation of China (No 51809221 and No. 42177143), the Science Foundation for Distinguished Young Scholars of Sichuan Province (Grant No. 2020JDJQ0011) and the opening project (No. KFJJ20-06M) of State Key Laboratory of Explosion Science and Technology (Beijing Institute of Technology).

Institutional Review Board Statement: Not applicable.

Data Availability Statement: The microseismic data related to this research is confidential and cannot be made public.

Acknowledgments: Thanks are given to colleagues at the hydropower station for their valuable contributions to the project. Finally, the authors would like to thank the editors and reviewers for their valuable comments and constructive suggestions.

Conflicts of Interest: The authors declare no conflict of interest.

\section{References}

1. Li, B.; Xu, N.; Dai, F.; Gu, G.; Ke, W. Microseismic monitoring and stability analysis for the large-scale underground caverns at the Wudongde hydropower station. Bull. Eng. Geol. Environ. 2020, 79, 3559-3573. [CrossRef]

2. Young, R.P.; Collins, D.S.; Reyes-Montes, J.M.; Baker, C. Quantification and interpretation of seismicity. Int. J. Rock Mech. Min. Sci. 2004, 41, 1317-1327. [CrossRef]

3. Hassani, H.; Hloušek, F.; Alexandrakis, C.; Buske, S. Migration-based microseismic event location in the Schlema-Alberoda mining area. Int. J. Rock Mech. Min. Sci. 2018, 110, 161-167. [CrossRef]

4. Barthwal, H.; Calixto, F.J.; Van der Baan, M. 3-D attenuation tomography from microseismicity in a mine. Geophys. J. Int. 2019, 219, 1805-1817. [CrossRef]

5. Young, R.P.; Collins, D.S. Seismic studies of rock fracture at the Underground Research Laboratory, Canada. Int. J. Rock Mech. Min. Sci. 2001, 38, 787-799. [CrossRef]

6. Krietsch, H.; Gischig, V.; Evans, K.; Doetsch, J.; Dutler, N.O.; Valley, B.; Amann, F. Stress measurements for an in situ stimulation experiment in crystalline rock: Integration of induced seismicity, stress relief and hydraulic methods. Rock Mech. Rock Eng. 2019, 52, 517-542. [CrossRef]

7. Feng, G.L.; Feng, X.T.; Chen, B.R.; Xiao, Y.X.; Yu, Y. A microseismic method for dynamic warning of rockburst development processes in tunnels. Rock Mech. Rock Eng. 2015, 48, 2061-2076. [CrossRef]

8. Zhang, Z.; Arosio, D.; Hojat, A.; Zanzi, L. Reclassification of microseismic events through hypocentre location: Case study on an unstable rock face in Northern Italy. Geosciences 2021, 11, 37. [CrossRef]

9. Zhang, Z.; Arosio, D.; Hojat, A.; Zanzi, L. Tomographic experiments for defining the 3D velocity model of an unstable rock slope to support microseismic event interpretation. Geosciences 2020, 10, 327. [CrossRef]

10. Huang, C.J.; Yin, H.Y.; Chen, C.Y.; Yeh, C.H.; Wang, C.L. Ground vibrations produced by rock motions and debris flows. J. Geophys. Res. Earth Surf. 2007, 112, 1-20. [CrossRef]

11. Helmstetter, A.; Garambois, S. Seismic monitoring of Schilienne rockslide (French Alps): Analysis of seismic signals and their correlation with rainfalls. J. Geophys. Res. Earth Surf. 2010, 115, 1-15. [CrossRef]

12. Burjánek, J.; Gassner-Stamm, G.; Poggi, V.; Moore, J.R.; Fäh, D. Ambient vibration analysis of an unstable mountain slope. Geophys. J. Int. 2010, 180, 820-828. [CrossRef] 
13. Denlinger, R.P.; Bufe, C.G. Reservoir conditions related to induced seismicity at The Geysers steam reservoir, northern California. Bull. Seismol. Soc. Am. 1982, 72, 1317-1327. [CrossRef]

14. Rutledge, J.T.; Phillips, W.S. Hydraulic stimulation of natural fractures as revealed by induced microearthquakes, Carthage Cotton Valley gas field, east Texas. Geophysics 2003, 68, 441-452. [CrossRef]

15. Zhao, Q.; Lisjak, A.; Mahabadi, O.; Liu, Q.; Grasselli, G. Numerical simulation of hydraulic fracturing and associated microseismicity using finite-discrete element method. J. Rock Mech. Geotech. Eng. 2014, 6, 574-581. [CrossRef]

16. Akono, A.T.; Druhan, J.L.; Dávila, G.; Tsotsis, T.; Jessen, K.; Fuchs, S.; Werth, C.J. A review of geochemical-mechanical impacts in geological carbon storage reservoirs. Greenh. Gases. 2019, 9, 474-504. [CrossRef]

17. Li, S.Y.; He, X.S.; Zhang, S.Q.; Lu, Q.H.; Jiang, X.Q.; Tong, X.H.; Li, G.J. Development and recent achievement of mining shock observation. Prog. Geophys. 2004, 19, 853-859.

18. Tang, L.Z.; Jian, Y.H.; Li, D.Y.; Wang, C.; Deng, L.F.; Chen, Y. Analysis of damage mechanism for surrounding rock based on microseismic moment tensor. Rock Soil Mech. 2017, 38, 1436-1444.

19. Dou, L.; Feng, L.; Cai, W.; Wang, H.; He, H.; Jiao, B.; Zhang, M. Seismo-acoustic precursor identification and comprehensive warning model for the catastrophic failure process of coal and rock. J. Min. Saf. Eng. 2020, 37, 960-976.

20. Zhu, Q.; Jiang, F.; Wei, Q.; Wang, B.; Liu, J.; Liu, X. An automatic method determining arrival times of microseismic P-phase in hydraulic fracturing of coal seam. Chin. J. Rock Mech. Eng. 2018, 37, 2319-2333.

21. Jiang, L.; Kong, P.; Zhang, P.; Shu, J.; Wang, Q.; Chen, L.; Wu, Q. Dynamic analysis of the rock burst potential of a longwall panel intersecting with a fault. Rock Mech. Rock Eng. 2020, 53, 1737-1754. [CrossRef]

22. Chen, B.R.; Feng, X.T.; Zeng, X.; Xiao, Y.; Zhang, Z.; Ming, H.; Feng, G. Real-time microseismic monitoring and its characteristic analysis during TBM tunneling in deep-buried tunnel. J. Rock Mech. Eng. 2011, 30, 275-283.

23. Feng, G.L.; Feng, X.T.; Chen, B.R.; Xiao, Y.X.; Zhao, Z.N. Effects of structural planes on the microseismicity associated with rockburst development processes in deep tunnels of the Jinping-II hydropower station, China. Tunn. Undergr. Space Technol. 2019, 84, 273-280. [CrossRef]

24. Liu, X.; Tang, C.; Li, L.; Lv, P.; Sun, R. Microseismic monitoring and stability analysis of the right bank slope at Dagangshan hydropower station after the initial impoundment. Int. J. Rock Mech. Min. Sci. 2018, 108, 128-141. [CrossRef]

25. Liu, F.; Ma, T.H.; Tang, C.; Chen, F. Prediction of rockburst in tunnels at the Jinping II hydropower station using microseismic monitoring technique. Tunn. Undergr. Space Technol. 2018, 81, 480-493. [CrossRef]

26. Xu, N.; Tang, C.; Li, L.; Zhou, Z.; Sha, C.; Liang, Z. Microseismic monitoring and stability analysis of the left bank slope in Jinping first stage hydropower station in southwestern China. Int. J. Rock Mech. Min. Sci. 2011, 48, 950-963. [CrossRef]

27. Li, B.; Ding, Q.F.; Xu, N.W.; Lei, Y.F.; Xu, Y.; Zhu, Z.P.; Liu, J.F. Mechanical response and stability analysis of rock mass in high geostress underground powerhouse caverns subjected to excavation. J. Cent. South Univ. 2020, 27, 2971-2984. [CrossRef]

28. Li, B.; Xu, N.; Dai, F.; Zhang, G.; Xiao, P. Dynamic analysis of rock mass deformation in large underground caverns considering microseismic data. Int. J. Rock Mech. Min. Sci. 2019, 122, 104078. [CrossRef]

29. Boatwright, J.; Fletcher, J.B. The partition of radiated energy between $P$ and $S$ waves. The partition of radiated energy between $P$ and S waves. Bull. Seismol. Soc. Am. 1984, 74, 361-376. [CrossRef]

30. Gutenberg, B.; Richter, C.F. Frequency of earthquakes in California. Bull. Seismol. Soc. Am. 1944, 34, 185-188. [CrossRef]

31. Legge, N.; Spottiswoode, S. Fracturing and microseismicity ahead of a deep gold mine stope in the pre-remnant and remnant stages of mining. In Proceedings of the 6th ISRM Congress, Montreal, QC, Canada, 30 August-3 September 1987; pp. 1071-1077. 